\title{
Effects of metformin on insulin resistance and metabolic disorders in tumor-bearing rats with advanced cachexia
}

\begin{tabular}{|c|c|}
\hline Journal: & Canadian Journal of Physiology and Pharmacology \\
\hline Manuscript ID & cjpp-2017-0171.R2 \\
\hline Manuscript Type: & Article \\
\hline Date Submitted by the Author: & 23-Aug-2017 \\
\hline Complete List of Authors: & $\begin{array}{l}\text { de Fatima Silva, Flaviane; State University of Londrina } \\
\text { Ortiz-Silva, Milene; State University of Londrina } \\
\text { Galia, Winny Beatriz; State University of Londrina } \\
\text { Cassolla, Priscila; State University of Londrina } \\
\text { da Silva, Francemilson; University of São Paulo } \\
\text { Graciano, Maria Fernanda; State University of Londrina, Department of } \\
\text { Physiological Sciences } \\
\text { Carpinelli, Angelo; University of São Paulo } \\
\text { de Souza, Helenir; State University of Londrina }\end{array}$ \\
\hline Keyword: & $\begin{array}{l}\text { Cancer, Hypercatabolism, Hypoinsulinemia, Metabolic changes, Insulin } \\
\text { resistance }\end{array}$ \\
\hline $\begin{array}{l}\text { Is the invited manuscript for } \\
\text { consideration in a Special } \\
\text { Issue?: }\end{array}$ & N/A \\
\hline
\end{tabular}


Effects of metformin on insulin resistance and metabolic disorders in tumor-bearing rats with advanced cachexia

\section{Running title: Effects of metformin on insulin resistance and cancer cachexia}

Flaviane de Fatima Silva ${ }^{1}$, Milene Ortiz-Silva ${ }^{1}$, Winny Beatriz de Souza Galia ${ }^{1}$, Priscila Cassolla $^{1}$, Francemilson Goulart da Silva ${ }^{2}$, Maria Fernanda Rodrigues Graciano ${ }^{1}$, Angelo Rafael Carpinelli ${ }^{2}$, Helenir Medri de Souza ${ }^{1}$

${ }^{1}$ Department of Physiological Sciences, State University of Londrina, 86051-990, Londrina, PR, Brazil;

${ }^{2}$ Department of Physiology and Biophysics, University of São Paulo, 05508-900, São Paulo, SP, Brazil;

* To whom correspondence should be addressed:

Dr. Helenir Medri de Souza

Department of Physiological Sciences

State University of Londrina 86051-990

Londrina - PR, Brazil

FAX: +55 (43) 33714467

Email: hmedri@uel.br 


\begin{abstract}
Metformin (MET) is widely used in the correction of insulin (INS) resistance and metabolic abnormalities in type 2 diabetes. However, its effect on INS resistance and metabolic disorders associated with cancer cachexia is not established. We investigated the MET effects, isolated or associated with INS, on INS resistance and metabolic changes induced by Walker-256 tumor in rats with advanced cachexia. MET (500 mg.kg ${ }^{-1}$, oral) and MET + INS (NPH, 1.0 IU.kg $^{-}$ 1 , sc) were administered during 12 days, starting on the day of tumor cell inoculation. Tumorbearing rats showed adipose and muscle mass wasting, weight loss, anorexia, decreased Akt phosphorylation in retroperitoneal and mesenteric adipose tissue, peripheral INS resistance, hypoinsulinemia, reduced INS content and secretion from pancreatic islets and also inhibition of glycolysis, gluconeogenesis and glycogenolysis in liver. MET and MET + INS treatments did not prevent these changes. It can be concluded that treatments with MET and MET + INS did not prevent the adipose and muscle mass wasting and weight loss of tumor-bearing rats possibly by not improving INS resistance. Therefore, MET, used for the treatment of INS resistance in type 2 diabetes, is not effective in improving INS resistance in the advanced stage of cancer cachexia, evidencing that the drug does not have the same beneficial effect in these two diseases.
\end{abstract}

Key words: Cancer, Hypercatabolism, Hypoinsulinemia, Metabolic changes, Insulin resistance. 


\section{INTRODUCTION}

Cancer cachexia is a complex syndrome characterized by marked weight loss, anorexia, inflammation and changes in the metabolism of carbohydrates, lipids and proteins, being an important cause of mortality, since there is no effective treatment (Evans et al. 2008; Tisdale 2010; Vaughan et al. 2013; Porporato 2016).

The weight loss in cancer cachexia is a result of muscle and fat wasting due to hypercatabolism of proteins and lipids (Argilés et al. 2005; Evans et al. 2008; Tisdale 2010; Petruzzelli and Wagner 2016). The intense proteolysis and lipolysis is promoted by cachexia mediators, such as proteolysis inducing factor (PIF), lipid mobilizing factor (LMF) and cytokines such as tumor necrosis factor $\alpha(\mathrm{TNF} \alpha)$ and interleukins 1 (IL1) and 6 (IL6) (Mantovani et al. 2000; Argilés et al. 2005; Gordon et al. 2005; Patel and Patel 2016).

However, it is possible that insulin (INS) resistance present in cancer-bearing (Lundholm et al. 1978; Copeland et al. 1987; Honors and Kinzig 2012) also contributes to the establishment of cachexia, since INS has potent anabolic and anticatabolic effects on protein and lipid (Wilcox 2005; Chevalier and Farsijani 2014). Few studies have investigated the effects of INS sensitivities on muscle and fat wasting and other metabolic changes associated with cancer cachexia (Ropelle et al. 2007; Asp et al. 2010).

Metformin (MET) is an INS sensitizer used worldwide for the treatment of type 2 diabetes. Its INS sensitizing effect is mainly attributed to the stimulation of adenosine monophosphate activated kinase protein (AMPK) (Zhou et al. 2001; Hadad et al. 2013). Once activated, AMPK stimulates the INS signaling pathway proteins, such as protein kinase 3 (PI3K) and protein kinase B (Akt or PKB) (Kurth-Kraczek et al. 1999; Jakobsen et al. 2001). METactivated AMPK also stimulates fatty acid oxidation and thereby reduces lipid (free fatty acids) interference on INS sensitivity in patients with type 2 diabetes (Zhou et al. 2001; Hawley et al. 2010; Andújar-Plata et al. 2012). Free fatty acids impair INS signaling by decreasing the proteins phosphorylation of INS signaling pathway, such as the Akt (Delarue and Magnan 2007). 
Although the MET effects as an INS sensitizer in type 2 diabetes are well understood, its effects on INS resistance, as well as on several metabolic abnormalities and cancer-associated cachexia have been poorly investigated.

Considering that Walker-256 tumor-bearing rats exhibit INS resistance and hypoinsulinemia, which may contribute to the metabolic disorders and cachexia in these animals (Fernandes et al. 1990; De Souza et al. 2015a), the aim of this study was to evaluate the MET effects, isolated or associated with INS, on INS signaling pathway proteins (Akt), INS resistance and metabolic disorders in Walker-256 tumor-bearing rats with advanced cachexia.

\section{MATERIALS AND METHODS}

\subsection{Drugs and chemicals}

Metformin (Glifage $\left.{ }^{\circledR}\right)$ was purchased from Merck and Co. (Darmstad, Germany) and NPH INS (Humulin ${ }^{\circledR}$ ) and regular INS (Humalog®) from Eli Lilly (Rio de Janeiro, Brazil). Primary and secondary antibodies were acquired from Cell Signaling Technology® (Danvers, USA), Abcam ${ }^{\circledR}$ (Cambridge, USA), Santa Cruz Biotechnology ${ }^{\circledR}$ (Dallas, USA) or Jackson ImunoReaserch Laboratories, Inc. (West Grove, USA). Protease inhibitors were acquired from AMRESCO ${ }^{\circledR}$ LLC (Solon, USA). Radioactive INS was purchased from PerkinElmer (Massachusetts, USA). The perfusion fluid salts and other chemicals were obtained from Sigma Chemical Co. (St Louis), Merck and Co. (Darmstadt, Germany), Reagen (Rio de Janeiro, Brazil) or Laborclin (Pinhais, Brazil).

\subsection{Animals and Walker-256 tumor inoculation}

The experimental protocols were approved by the Ethics Committee for Animal Use of the State University of Londrina (CEUA/UEL, register number 09161) and followed the Guide for the Care and Use of Laboratory Animals (Institute for Laboratory Animal Research, National Research Council, Washington, DC, National Academy Press, no. 85-23, revised 1996). 
Male Wistar rats (220-230 g), kept in collective boxes, $23 \pm 2{ }^{\circ} \mathrm{C}$, light/dark cycle of 12 h, with free access to water and standard rodent chow (Nuvilab, CR-1 Nuvital ${ }^{\circledR}$, Colombo, Brazil) were used in all experiments. Walker-256 carcinosarcoma cells were maintained as previously described (Cassolla et al. 2012). For tumor inoculation, $8 \times 10^{7}$ tumor cells were suspended in phosphate buffered salin e (PBS: $16.5 \mathrm{mM}$ phosphate, $137 \mathrm{mM} \mathrm{NaCl}, 2.7 \mathrm{mM} \mathrm{KCl}$, pH 7.4) and inoculated subcutaneously in the right flank of rats (tumor-bearing rats). Healthy rats were injected with PBS in the same place.

\subsection{Treatment protocol}

Walker-256 tumor-bearing rats were treated with MET (500 mg. $\mathrm{kg}^{-1}$, oral gavage), alone or in association with INS (NPH, $\left.1.0 \mathrm{UI}^{\mathrm{kg}}{ }^{-1}, \mathrm{sc}\right)$, once a day $(17: 00 \mathrm{pm})$ for 12 days, since the day of tumor cells inoculation. Doses were based on previous study (Ropelle et al. 2007; Takada et al. 2008). MET was daily dissolved in water and INS was diluted in saline $(0.9 \% \mathrm{NaCl})$. Control rats (tumor-bearing and healthy) received vehicles.

The experiments were performed on day 12 after tumor cells inoculation, $3 \mathrm{~h}$ after the last treatment, in fed rats. The experiments for evaluation of glycolysis and gluconeogenesis were performed in rats fasted for 24 hours.

\subsection{Assessment of cachexia-anorexia parameters and tumor growth}

Food intake was measured (day 11) by the difference between the amount of feed supplied and the remainder after $24 \mathrm{~h}$. On day 12, rats were weighed, anesthetized with thiopental (50 mg. $\mathrm{kg}^{-1}$, ip) and laparotomized to collect of blood samples from the inferior vena cava to evaluate the concentrations of plasma INS by radioimmunoassay (Yalow and Berson 1960). Thereafter, the rats were euthanatized and retroperitoneal and mesenteric adipose tissue and gastrocnemius and extensor digitorum longus (EDL) muscle were also carefully removed, weighed, quickly frozen in liquid nitrogen and stored at $-80^{\circ} \mathrm{C}$ for protein analysis. The pancreas 
also was removed for analysis of islet INS secretion and content. The tumor was dissected and weighed for assessment of tumor growth. The change in body mass was measured by the difference between the final body mass (day 12), discounted the tumor mass, and initial body mass (day 1).

\subsection{Western blotting to assess total Akt and p-Akt}

The retroperitoneal and mesenteric adipose tissues and the gastrocnemius muscle, stored at $-80^{\circ} \mathrm{C}$, were homogenized in buffer $(137 \mathrm{mM} \mathrm{NaCl}, 2.7 \mathrm{mM} \mathrm{KCl}, 1 \mathrm{mM} \mathrm{MgCl} 2,1 \mathrm{mM}$ EDTA, $5 \mathrm{mM} \mathrm{Na}_{4} \mathrm{P}_{2} \mathrm{O}_{7}, 10 \mathrm{mM} \mathrm{NaF}$, Triton X100 1\%, glycerol 10\%, $0.5 \mathrm{mM} \mathrm{Na}_{3} \mathrm{VO}_{4}, 20 \mathrm{mM}$ Tris, pH 7.8) containing $0.2 \mathrm{mM}$ of protease inhibitors cocktails (PIC) and phenylmethylsulfonyl fluoride (PMSF). The homogenate was centrifuged $\left(15294 \mathrm{~g}, 40 \mathrm{~min}, 4^{\circ} \mathrm{C}\right)$ and the total proteins of the supernatant were quantified (Bradford 1976). Equal amounts of total protein $(80 \mu \mathrm{g})$ diluted in Laemmli buffer, were applied to $10 \%$ polyacrylamide gel, submitted to electrophoresis (SDS-PAGE) and transference to nitrocellulose membrane. The membranes were incubated with primary antibody $(1: 1000)$ anti-Akt (Cell Signaling ${ }^{\circledR}$, catalog $\left.n^{\circ} 9272\right)$, anti-phospho-Akt ${ }^{\text {Ser473 }}$ (Cell Signaling ${ }^{\circledR}$, catalog $n^{\circ}$ 9271) or anti- $\gamma$-tubulin (Sigma ${ }^{\circledR}$, catalog $n^{\circ}$ T5326) overnight at $4^{\circ} \mathrm{C}$, followed by incubation with secondary antibody conjugate to peroxidase $(1: 5000)$ and chemiluminescence detection with peroxidase substrate (ECL) in Amersham Image ${ }^{\circledR}$ photodocumentator. The density of the blots was analyzed in Image J software (National Institutes of Health, USA) and expressed in arbitrary units (AU) after normalization by constitutive protein $\gamma$-tubulin.

\subsection{Assessment of INS secretion and content in pancreatic islets}

Pancreatic islets were isolated by pancreas digestion with collagenase as previously described (Lacy and Kostianovsky 1967). Groups of 5 islets were pre-incubated at $37^{\circ} \mathrm{C}$ during $30 \mathrm{~min}$ in Krebs-Henseleit $(\mathrm{KH})$ with $0.2 \%$ bovine serum albumin (BSA) and 5.6 mmol.L ${ }^{-1}$ 
glucose. Thereafter, islets were incubated at $37^{\circ} \mathrm{C}$ during $1 \mathrm{~h}$ in $\mathrm{KH}$ with $0.2 \% \mathrm{BSA}$ in different concentrations of glucose $(5.6,11.1$ or $16.7 \mathrm{mM})$. For total INS content, islets in each well were disrupted in acid ethanol solution (1.4\% chloridric acid and $74 \%$ ethanol) and sonicated (3 pulses of 5 seconds). At the end of the experiments, the medium was collected and INS was measured by radioimmunoassay (Yalow and Berson 1960).

\subsection{Insulin tolerance test (ITT)}

For the ITT, regular INS $\left(0.25 \mathrm{UI}_{\mathrm{kg}}{ }^{-1}\right)$ was injected into inferior vena cava in rats anesthetized with thiopental $\left(50 \mathrm{mg} \cdot \mathrm{kg}^{-1}\right.$; ip). Blood samples for evaluation of glycemia (Bergmeyer and Bernt 1974) were collected from inferior vena cava at 0 (basal), 5, 10 and 15 min after INS injection. The constant of plasma glucose disappearance (KITT), an indicator of INS peripheral response, was calculated as previously described (Seraphim et al. 2001; De Souza et al. 2015a).

\subsection{Liver perfusion to assess glycolysis, glycogenolysis and gluconeogenesis}

For in situ liver perfusion the rats were anesthetized with thiopental (50 mg. $\mathrm{kg}^{-1}$; ip). The portal and inferior cava vein were cannulated as previously described (De Morais et al. 2012; Da Rocha et al. 2013; De Souza et al. 2015b; Bassoli et al. 2015). The perfusion liquid, KrebsHenseleit buffer (KH: NaCl 115 mM, $\mathrm{NaHCO}_{3} 25 \mathrm{mM}, \mathrm{KCl} 5.8 \mathrm{mM}, 1.2 \mathrm{mM} \mathrm{Na} 2 \mathrm{SO}_{4}, 1.18 \mathrm{mM}$ $\mathrm{MgCl}_{2}, 1.2 \mathrm{mM} \mathrm{NaH} \mathrm{PO}_{4}$ and $\left.2.5 \mathrm{mM} \mathrm{CaCl}_{2}\right), \mathrm{pH} 7.4$ at $37{ }^{\circ} \mathrm{C}$ and saturated $\mathrm{O}_{2}: \mathrm{CO}_{2}(95: 5 \%)$ was introduced into portal vein $\left(4 \mathrm{ml} \cdot \mathrm{min}^{-1}\right.$ per gram of liver) and the liquid effluent of the liver was collected from inferior cava vein at 2 min intervals to assess the production of glucose (Bergmeyer and Bernt 1974), lactate (Gutmann and Wahlefeld 1974) and pyruvate (Czok and Lamprecht 1974).

For assessment of glycolysis and gluconeogenesis livers of 24 hours fasted rats (to deplete liver glycogen) were perfused with $\mathrm{KH}$ for 10 minutes followed by perfusion for 30 minutes with 
$\mathrm{KH}+20 \mathrm{mM}$ glucose (glycolysis evaluation) or $\mathrm{KH}+2.5 \mathrm{mM}$ alanine (gluconeogenesis evaluation). For the assessment of glycogenolysis livers of fed rats were perfused for 30 minutes with KH. Glycolysis was calculated as the sum of pyruvate plus lactate production (lactate + pyruvate) and glycogenolysis as the sum of glucose production plus the half-sum of lactate and pyruvate production [glucose $+1 / 2$ (lactate + pyruvate)] (Miksza et al. 2013; Da Rocha et al. 2014; De Souza et al. 2015b).

\subsection{Statistical analysis}

Data were tested for normal distribution (Shapiro-Wilk test) and homogeneity of variances (Brown Forsythe test) and appropriate statistical test (One-Way ANOVA followed by Tukey) were employed. Statistical analysis were carried out with the program GraphPad Prism 6.0 , at a significance level of $5 \%(\mathrm{p}<0.05)$. Data were expressed as mean \pm standard error of the mean (SEM).

\section{RESULTS}

The p-Akt:total Akt ratio of retroperitoneal (Figure 1A) and mesenteric (Figure 1B) adipose tissue, but not the gastrocnemius muscle (Figure 1C), was lower in tumor-bearing rats compared to healthy rats. MET and MET + INS treatments had no effect on p-Akt:total Akt of these tissues.

Tumor-bearing rats had reduced INS peripheral response compared to healthy rats (Figure 2A), as evidenced by lower kITT (Figure 2B). MET and MET + INS did not improve the INS resistance of tumor-bearing rats (Figure 2B).

Blood INS (Figure 3A), INS secretion from islets incubated with $16.7 \mathrm{mM}$ glucose (Figure 3B) and INS intracellular content of islets (Figure 3C) were lower in tumor-bearing rats compared to healthy rats and were not improved by MET and MET + INS treatments (Figures $3 \mathrm{~A}, 3 \mathrm{~B}$ and $3 \mathrm{C})$. 
Tumor-bearing rats showed tumor mass about $25 \mathrm{~g}$, which was associated with body mass loss, retroperitoneal and mesenteric adipose mass wasting, gastrocnemius and EDL muscle mass wasting and anorexia (Table 1). MET and MET + INS had no effect on tumor growth or parameters of cachexia and anorexia (Table 1).

Regarding the hepatic parameters, tumor-bearing rats showed reduced production of lactate (Figure 4A) and pyruvate (Figure 4B) and consequently of glycolysis (Figure 4C) from exogenous glucose, compared to healthy rats. MET and MET + INS had no effect on these parameters, as shown by AUCs (Figure 4D).

Tumor-bearing rats showed decreased hepatic glucose production (Figures 5A) and glycogenolysis (Figures 5B) compared to healthy rats. MET treatment did not change these parameters, but MET + INS increased glucose production and glycogenolysis in tumor-bearing rats compared to rats with tumor untreated, as evidenced by AUCs (Figures 5C and 5D).

Finally, tumor-bearing rats showed reduced production of glucose (Figure 6A), lactate (Figure 6B) and pyruvate (Figure 6C) compared to healthy rats. MET and MET + INS did not change glucose production but increased the lactate and pyruvate production of tumor-bearing rats, as shown by AUCs (Figure 6D).

\section{DISCUSSION}

Given that MET reduces INS resistance and improves metabolic abnormalities in type 2 diabetes, we decided to investigate whether these beneficial effects of MET also occur in Walker256 tumor-bearing rats with advanced cachexia. We showed that treatment with MET or MET + INS did not improve INS resistance and the metabolic disorders induced by the Walker-256 tumor at this advanced stage of the cachectic syndrome.

Tumor-bearing rats showed reduced Akt phosphorylation in retroperitoneal and mesenteric adipose tissue but not in the gastrocnemius muscle (Figure 1). Gastrocnemius p-Akt was not reduced probably because of the compensatory overload of this muscle, caused by the 
reduced capacity of support and locomotion of contralateral limb, where the tumor was located (Bodine et al. 2001).

Consistent with the reduction of p-Akt in adipose tissue, tumor-bearing rats showed reduced INS peripheral response (Figure 2), indicating INS resistance. INS resistance in cancer has been related to the production of cytokines (TNF $\alpha$ and IL6) and to excess of blood free fatty acids resulting from intense lipolysis (Yoshikawa et al. 1999). These factors interfere in the INS signal transduction, since they change the protein phosphorylation of INS signaling cascade as the Akt (Kanety et al. 1995; Boden 2002; Kim et al. 2004; Delarue and Magnan 2007). MET and MET + INS treatments did not improve the INS signal transduction in adipose tissue, as indicated by the decreased Akt phosphorylation (Figure 1), and nor the INS peripheral response (Figure 2).

Tumor-bearing rats also showed hypoinsulinemia (Figure 3A), confirming previous findings (Fernandes et al. 1990), which is probably consequence of decreased INS secretion (Figure 3B) and synthesis (Figure 3C) by pancreatic- $\beta$ cells. Treatments with MET e MET + INS did not improve the secretory dysfunction and decreased INS synthesis of the islet and nor hypoinsulinemia (Figure 3). INS supplementation did not change the hypoinsulinemia of tumorbearing rats, probably due to its metabolism. It is noteworthy that blood INS was evaluated $3 \mathrm{~h}$ after the last treatment with low INS dose.

Consistent with the lack of treatments effect on INS resistance and hypoinsulinemia, MET and MET + INS treatments did not prevent weight loss, and adipose (retroperitoneal and mesenteric) and muscle (gastrocnemius and EDL muscle) mass wasting (Table 1). Weight loss in cancer cachexia is attributed to intense muscle proteolysis and lipolysis, due to the action of factors such as PIF, LMF and cytokines (TNFa, IL1 and IL6), which activate proteolytic and lipolytic pathways, as well as reducing protein synthesis and adipogenesis (Mantovani et al. 2000; Gordon et al. 2005; Patel and Patel 2016).

Weight loss in patients and animals with cancer is also attributed to anorexia. Anorexia in cancer appears to be related to the hypothalamic effect of cytokines (TNF $\alpha$ and IL6) that stimulate 
the release of anorexigenic factors, such as corticotrophin releasing factor $(\mathrm{CRH})$, and reduce the release of orexigenic factors such as neuropeptide Y (NPY) (Martignoni 2003; Argilés et al. 2005; Patra and Arora 2012). In our study, treatment with MET + INS did not prevent tumor-induced anorexia (Table 1). MET and MET + INS treatments also did not change tumor growth (Table 1), corroborating with other studies (Ropelle et al. 2007).

Another parameter affected by the tumor and regulated by INS, which could be benefited by treatment with an INS sensitizer is the glucose metabolism in the liver. Tumor-bearing rats showed inhibition of glycolysis from exogenous glucose (Figure 4), corroborating our previous studies (Miksza et al. 2013; De Souza et al. 2015b). These results are consistent with inhibition of glucokinase observed in rats with Walker-256 tumor (Vicentino et al. 2002). The glucokinase inhibition decreases glucose uptake by liver and may have contributed to the lower peripheral response to INS (KITT) in tumor-bearing rats (Figure 2). Although MET stimulates ATPgenerating pathways, MET and MET + INS treatments did not prevent inhibition of glycolysis in tumor-bearing rats (Figure 4), probably due to inhibition of glucokinase (Vicentino et al. 2002).

Tumor-bearing rats also showed inhibition of hepatic glucose production and glycogenolysis (Figure 5), results that reflect the low glycogen content in liver, as observed in our studies (Cassolla et al. 2012). MET treatment did not change glucose production and glycogenolysis, but MET + INS treatment increased these parameters (Figure 5), probably because INS increased glycogen content and MET activated glycogenolysis (Salani et al. 2014).

In addition, tumor-bearing rats showed inhibition of hepatic gluconeogenesis from alanine (Figure 6), confirming our previous studies (Moreira et al. 2013; De Souza et al. 2015b). MET treatment did not change the reduced glucose production, but MET + INS treatment increased lactate and pyruvate production, which is reduced in tumor-bearing rats (Figure 6), an effect that may be due to the stimulatory action of MET on the catabolism of glucose (glycolysis) generated by gluconeogenesis (Salani et al. 2014). 
It can be concluded that MET and MET + INS treatments did not prevent the adipose and muscle mass wasting and weight loss of the tumor-bearing rats possibly by not improving INS resistance. Therefore, MET, widely used for the treatment of INS resistance in type 2 diabetes, is not effective in improving INS resistance in the advanced stage of cancer cachexia, evidencing that the drug does not have the same beneficial effect in these two diseases.

Although some studies (Fonseca et al. 2011, Franco et al. 2014, Oliveira and GomesMarcondes 2016) show beneficial effects of MET treatment in Walker-256 tumor-bearing rats, it is noteworthy that the treatment protocols, the animal model (obese tumor-bearing rats), the stage of cachexia and/or age of the animals were different from those used in the present study. 
Acknowledgments: The authors thank Dr. Maria Tereza Nunes (Department of Physiology and Biophysics, University of São Paulo), for kindly provided her laboratory for molecular analysis.

\section{Conflict of interest}

The authors declare that there are no conflicts of interest.

Funding: Research supported by Coordenação de Aperfeiçoamento de Pessoal de Nível Superior (CAPES - Scholarship) e Fundação Araucária (grant number 186/2013). 


\section{REFERENCES}

Andújar-Plata, P., Pi-Sunyer, X., and Laferrère, B. 2012. Metformin effects revisited. Diabetes Research and Clinical Practice, 95(1), 1-9. http://doi.org/10.1016/j.diabres.2011.09.022

Argilés, J. M., Busquets, S., Felipe, A., and López-Soriano, F. J. 2005. Molecular mechanisms involved in muscle wasting in cancer and ageing: Cachexia versus sarcopenia. International Journal of Biochemistry and Cell Biology, 37(5), 1084-1104. http://doi.org/10.1016/j.biocel.2004.10.003

Asp, M. L., Tian, M., Wendel, A. A., and Belury, M. A. 2010. Evidence for the contribution of insulin resistance to the development of cachexia in tumor-bearing mice. International Journal of Cancer, 126(3), 756-63. http://doi.org/10.1002/ijc.24784

Bassoli, B. K., Cassolla, P., Borba-Murad, G. R., Constantin, J., Salgueiro-Pagadigorria, C. L., Bazotte, R. B., and de Souza, H. M. 2015. Instant coffee extract with high chlorogenic acids content inhibits hepatic G-6-Pase in vitro, but does not reduce the glycaemia. Cell Biochemistry and Function, 33(4), 183-187. http://doi.org/10.1002/cbf.3099

Bergmeyer, H., and Bernt, E. 1974. Determination of glucose with glucose-oxidase and peroxidase. In - Methods of Enzymatic Analysis (2nd ed). Edited by Bergmeyer H., 12051215.

Boden, G. 2002. Interaction between free fatty acids and glucose metabolism. Current Opinion in Clinical Nutrition and Metabolic Care, 5(5), 545-549. http://doi.org/10.1097/00075197-200209000-00014

Bodine, S. C., Stitt, T. N., Gonzalez, M., Kline, W. O., Stover, G. L., Bauerlein, R. et al. 2001. Akt/mTOR pathway is a crucial regulator of skeletal muscle hypertrophy and can prevent muscle atrophy in vivo. Nature Cell Biology, 3(11), 1014-1019. http://doi.org/10.1038/ncb1101-1014

Bradford, M. M. 1976. A rapid and sensitive method for the quantitation of microgram quantities of protein utilizing the principle of protein-dye binding. Analytical Biochemistry, 72(1-2), 248-254. http://doi.org/10.1016/0003-2697(76)90527-3

Cassolla, P., Moreira, C. C. L., Liboni, T. F., Zaia, C. T. B. V., Borba-Murad, G. R., Bazotte, R. B., and de Souza, H. M. 2012. Changes in blood metabolic parameters during the development of Walker-256 tumour-induced cachexia in rats are not caused by decreased food intake. Cell Biochemistry and Function, 30(4), 265-270. http://doi.org/10.1002/cbf.2792

Copeland, G. P., Leinster, S. J., Davis, J. C., and Hipkin, L. J. 1987. Insulin resistance in patients with colorectal cancer. British Journal of Surgery, 74(11), 1031-1035.

http://doi.org/10.1002/bjs.1800741124

Czok, R., and Lamprecht, W. 1974. Pyruvate, phosphoenolpyruvate and D-glycerate-2phosphate. In - Methods of Enzymatic Analysis (2nd ed). Edited by Bergmeyer H., 14461448 .

Da Rocha, A. F., Liboni, T. F., Kurauti, M. A., De Souza, C. O., Miksza, D. R., Moreira, C. C. L. 
et al. 2014. Tumor necrosis factor alpha abolished the suppressive effect of insulin on hepatic glucose production and glycogenolysis stimulated by cAMP. Pharmacological Reports, 66(3), 380-385. http://doi.org/10.1016/j.pharep.2013.12.005

Da Rocha, A. F., Liboni, T. F., Moreira, C. C. L., Miksza, D. R., De Souza, C. O., De Fatima Silva, F. et al. 2013. Inhibitory effect of tumor necrosis factor $\alpha$ on gluconeogenesis in perfused rat liver. Molecular and Cellular Biochemistry, 375(1-2), 89-96. http://doi.org/10.1007/s11010-012-1531-4

De Morais, H., Cassola, P., Moreira, C. C. L., Bôas, S. K. F. V., Borba-Murad, G. R., Bazotte, R. B., and De Souza, H. M. 2012. Decreased response to c AMP in the glucose and glycogen catabolism in perfused livers of Walker-256 tumor-bearing rats. Molecular and Cellular Biochemistry, 368(1-2), 9-16. http://doi.org/10.1007/s11010-012-1337-4

De Souza, C. O., Kurauti, M. A., de Fatima Silva, F., de Morais, H., Borba-Murad, G. R., de Andrade, F. G., and de Souza, H. M. 2015. Effects of celecoxib and ibuprofen on metabolic disorders induced by Walker-256 tumor in rats. Molecular and Cellular Biochemistry, 399(1-2), 237-246. http://doi.org/10.1007/s11010-014-2250-9

De Souza, C. O., Kurauti, M. A., de Fatima Silva, F., de Morais, H., Curi, R., Hirabara, S. M., ... de Souza, H. M. 2015. Celecoxib and Ibuprofen Restore the ATP Content and the Gluconeogenesis Activity in the Liver of Walker-256 Tumor-Bearing Rats. Cellular Physiology and Biochemistry, 36(4), 1659-1669. http://doi.org/10.1159/000430326

Delarue, J., and Magnan, C. 2007. Free fatty acids and insulin resistance. Current Opinion in Clinical Nutrition and Metabolic Care, 10(2), 142-148.

http://doi.org/10.1097/MCO.0b013e328042ba90

Evans, W. J., Morley, J. E., Argilés, J., Bales, C., Baracos, V., Guttridge, D. et al. 2008. Cachexia: A new definition. Clinical Nutrition, 27(6), 793-799. http://doi.org/10.1016/j.clnu.2008.06.013

Fernandes, L. C., Machado, U. F., Nogueira, C. R., Carpinelli, A. R., and Curi, R. 1990. Insulin secretion in Walker 256 tumor cachexia. American Journal of Physiology Endocrinology and Metabolism, 258(6), E1033-E1036 . https://doi.org/10.1152/ajpendo.1990.258.6.E1033

Gordon, J. N., Green, S. R., and Goggin, P. M. 2005. Cancer cachexia. QJM: An International Journal of Medicine, 98(11), 779-88. http://doi.org/10.1093/qjmed/hci127

Gutmann, I., and Wahlefeld, A. 1974. L-(+)-lactate determination with lactate dehydrogenase and NAD. In - Methods of Enzymatic Analysis (2nd ed). Edited by Bergmeyer H., 1464-1468.

Hadad, S. M., Hardie, D G, Appleyard, V, and Thompson, A M. 2013. Effects of metformin on breast cancer cell proliferation, the AMPK pathway and the cell cycle. Clinical and Translational Oncology, 16(8):746-52. doi: 10.1007/s12094-013-1144-8

Hawley, S. a, Ross, F. a, Chevtzoff, C., Green, K. a, Evans, A., Fogarty, S. et al. 2010. Use of cells expressing gamma subunit variants to identify diverse mechanisms of AMPK activation. Cell Metabolism, 11(6), 554-65. http://doi.org/10.1016/j.cmet.2010.04.001

Honors, M. A., and Kinzig, K. P. 2012. The role of insulin resistance in the development of 
muscle wasting during cancer cachexia. Journal of Cachexia, Sarcopenia and Muscle, 3(1), 5-11. http://doi.org/10.1007/s13539-011-0051-5

Jakobsen, S. N., Hardie, D. G., Morrice, N., and Tornqvist, H. E. 2001. 5'-AMP-activated Protein Kinase Phosphorylates IRS-1 on Ser-789 in Mouse C2C12 Myotubes in Response to 5Aminoimidazole-4-carboxamide Riboside. Journal of Biological Chemistry, 276(50), 46912-46916. http://doi.org/10.1074/jbc.C100483200

Kanety, H., Feinstein, R., Papa, M. Z., Hemi, R., and Karasik, A. 1995. Tumor necrosis factor $\alpha-$ induced phosphorylation of insulin receptor substrate-1 (IRS-1). The Journal of Biological Chemistry, 270(40), 23780-23784. http://doi.org/10.1074/jbc.270.40.23780

Kim, H., Higashimori, T., Park, S., Choi, H., Dong, J., Kim, Y. et al. 2004. Differential Effects of Interleukin-6 and -10 on Skeletal Muscle and Liver Insulin Action In Vivo. Diabetes, 53(4), 1060-1067. https://doi.org/10.2337/diabetes.53.4.1060

Kurth-Kraczek, E. J., Hirshman, M. F., Goodyear, L. J., and Winder, W. W. 1999. 5’ AMPactivated protein kinase activation causes GLUT4 translocation in skeletal muscle. Diabetes, 48(8), 1667-1671. https://doi.org/10.2337/diabetes.48.8.1667

Lacy, P. E., and Kostianovsky, M. 1967. Method for the isolation of intact islets of Langerhans from the rat pancreas. Diabetes, 16(1), 35-39. http://doi.org/10.2337/diab.16.1.35

Lundholm, K., Holm, G., and Schersten, T. 1978. Insulin resistance in patients with cancer. Cancer Research, 38(12), 4665-4670.

Mantovani, G., Macciò, A., Mura, L., Massa, E., Mudu, M. C., Mulas, C. et al. 2000. Serum levels of leptin and proinflammatory cytokines in patients with advanced-stage cancer at different sites. Journal of Molecular Medicine, 78(10), 554-561. http://doi.org/10.1007/s001090000137

Martignoni, M. E. 2003. Cancer cachexia. Nutritional Therapy and Metabolism, 24(2), 64-74. http://doi.org/10.1097/MOG.0b013e3283347e77

Miksza, D. R., De Souza, C. O., De Morais, H., Da Rocha, A. F., Borba-Murad, G. R., Bazotte, R. B., and De Souza, H. M. 2013. Effect of infliximab on metabolic disorders induced by Walker-256 tumor in rats. Pharmacological Reports, 65(4), 960-969. http://doi.org/10.1007/s11010-014-2250-9

Moreira, C. C. L., Cassolla, P., Dornellas, A. P. S., de Morais, H., de Souza, C. O., Borba-Murad, G. R. et al. 2013. Changes in liver gluconeogenesis during the development of Walker-256 tumour in rats. International Journal of Experimental Pathology, 94(1), 47-55. http://doi.org/10.1111/iep.12002

Patel, H. J., and Patel, B. M. 2017. TNF- $\alpha$ and cancer cachexia: Molecular insights and clinical implications. Life Sciences, 170(2), 56-63. http://doi.org/10.1016/j.1fs.2016.11.033

Patra, S. K., and Arora, S. 2012. Integrative role of neuropeptides and cytokines in cancer anorexia-cachexia syndrome. Clinica Chimica Acta, 413(13), 1025-1034. http://doi.org/10.1016/j.cca.2011.12.008

Petruzzelli, M., and Wagner, E. F. 2016. Mechanisms of metabolic dysfunction in cancer- 
associated cachexia. Genes and Development, 30(5):489-501.

http://doi.org/10.1101/gad.276733.115

Porporato, P. E. 2016. Understanding cachexia as a cancer metabolism syndrome. Oncogenesis, 5(2), e200. http://doi.org/10.1038/oncsis.2016.3

Ropelle, E. R., Pauli, J. R., Zecchin, K. G., Ueno, M., de Souza, C. T., Morari, J. et al. 2007. A central role for neuronal adenosine 5'-monophosphate-activated protein kinase in cancerinduced anorexia. Endocrinology, 148(11), 5220-5229. http://doi.org/10.1210/en.20070381

Salani, B., Rio, A. D., Marini, C., Sambuceti, G., Cordera, R., and Maggi, D. 2014. Metformin, cancer and glucose metabolism. Endocrine Related Cancer, 21(6), R461-R471. http://doi.org/10.1530/ERC-14-0284

Seraphim, P. M., Nunes, M. T., and Machado, U. F. 2001. GLUT4 protein expression in obese and lean 12-month-old rats: Insights from different types of data analysis. Brazilian Journal of Medical and Biological Research, 34(10), 1353-1362. http://doi.org/10.1590/S0100-879X2001001000018

Takada, J., Fonseca-Alaniz, M. H., de Campos, T. B. F., Andreotti, S., Campana, A. B., Okamoto, M. et al. 2008. Metabolic recovery of adipose tissue is associated with improvement in insulin resistance in a model of experimental diabetes. The Journal of Endocrinology, 198(1), 51-60. http://doi.org/10.1677/JOE-08-0072

Tisdale, M. J. 2010. Cancer cachexia. Current Opinion in Gastroenterology, 26(2), 146-51. http://doi.org/10.1097/MOG.0b013e3283347e77

Vaughan, V. C., Martin, P., and Lewandowski, P. A. 2013. Cancer cachexia: Impact, mechanisms and emerging treatments. Journal of Cachexia, Sarcopenia and Muscle, 4(2), 95-109. http://doi.org/10.1007/s13539-012-0087-1

Vicentino, C., Constantin, J., Aparecido Stecanella, L., Bracht, A., and Yamamoto, N. S. 2002. Glucose and glycogen catabolism in perfused livers of Walker-256 tumor-bearing rats and the response to hormones. Pathophysiology, 8(3), 175-182. http://doi.org/10.1016/S09284680(02)00003-2

Yalow, R. S., and Berson, S. A.1960. Immunoassay of endogenous plasma insulin in man. The Journal of Clinical Investigation, 39(7), 1157-75. http://doi.org/10.1172/JCI104130

Yoshikawa, T., Noguchi, Y., Doi, C., Makino, T., Okamoto, T., and Matsumoto, A. 1999. Insulin resistance was connected with the alterations of substrate utilization in patients with cancer. Cancer Letters, 141(1-2), 93-8. http://dx.doi.org/10.1016/S0304-3835(99)00086-5

Zhou, G., Myers, R., Li, Y., Chen, Y., Shen, X., Fenyk-Melody, J. et al. 2001. Role of AMPactivated protein kinase in mechanism of metformin action. Journal of Clinical Investigation, 108(8), 1167-1174. http://doi.org/10.1172/JCI200113505 
Table 1. Tumor mass, initial weight, final weight (excluding tumor weight), change of body mass, retroperitoneal and mesenteric fat mass, gastrocnemius and EDL muscle mass and food intake of healthy and Walker-256 tumor-bearing rats treated with metformin (Tumor + MET), metformin plus insulin (Tumor + MET + INS) or vehicles during 12 days.

\begin{tabular}{|c|c|c|c|c|}
\hline Parameter & Healthy & Tumor & $\begin{array}{l}\text { Tumor } \\
\text { MET }\end{array}$ & $\begin{array}{c}\text { Tumor } \\
\text { MET+ INS }\end{array}$ \\
\hline Tumor mass (g) & --- & $\begin{array}{c}24,72 \pm 1,32 \\
(21)\end{array}$ & $\begin{array}{l}26,86 \pm 2,39 \\
(17)\end{array}$ & $\begin{array}{l}27,48 \pm 2,14 \\
\quad(17)\end{array}$ \\
\hline Initial weight (g) & $\begin{array}{l}219,7 \pm 3,24 \\
\quad(10)\end{array}$ & $\begin{array}{l}219,6 \pm 2,36 \\
\quad(23)\end{array}$ & $\begin{array}{l}222,4 \pm 2,61 \\
\quad(17)\end{array}$ & $\begin{array}{l}224,0 \pm 2,67 \\
\quad(17)\end{array}$ \\
\hline Final weight (g) & $\begin{array}{l}261,4 \pm 3,99 \\
\quad(10)\end{array}$ & $\begin{array}{c}213,2 \pm 4,51 * * * \\
(23)\end{array}$ & $\begin{array}{c}206,2 \pm 5,97 * * * \\
(17)\end{array}$ & $\begin{array}{c}208,0 \pm 5,66^{* * *} \\
(17)\end{array}$ \\
\hline Change body mass (g) & $\begin{array}{l}41,7 \pm 2,59 \\
\quad(10)\end{array}$ & $\begin{array}{c}-6,4 \pm 3,43 * * * \\
(23)\end{array}$ & $\begin{array}{c}-16,2 \pm 4,67 * * * \\
(17)\end{array}$ & $\begin{array}{c}-16,0 \pm 3,76^{* * *} \\
(17)\end{array}$ \\
\hline Retroperitoneal fat ( $\mathrm{g} \%$ ) & $\begin{array}{c}0,772 \pm 0,053 \\
\text { (9) }\end{array}$ & $\begin{array}{c}0,544 \pm 0,038^{*} \\
(21)\end{array}$ & $\begin{array}{c}0,414 \pm 0,052 * * * \\
(16)\end{array}$ & $\begin{array}{c}0,371 \pm 0,039 * * * \\
(17)\end{array}$ \\
\hline Mesenteric fat (g\%) & $\begin{array}{c}0,463 \pm 0,024 \\
\text { (9) }\end{array}$ & $\begin{array}{c}0,334 \pm 0,021^{* *} \\
(20)\end{array}$ & $\begin{array}{c}0,324 \pm 0,036^{* *} \\
(17)\end{array}$ & $\begin{array}{c}0,282 \pm 0,027 * * * \\
(17)\end{array}$ \\
\hline $\begin{array}{c}\text { Gastrocnemius muscle } \\
(\mathrm{g} \%)\end{array}$ & $\begin{array}{c}0,639 \pm 0,014 \\
(15)\end{array}$ & $\begin{array}{c}0,582 \pm 0,011^{*} \\
(18)\end{array}$ & $\begin{array}{c}0,573 \pm 0,012 * * \\
(17)\end{array}$ & $\begin{array}{c}0,586 \pm 0,016^{*} \\
(17)\end{array}$ \\
\hline EDL muscle (g\%) & $\begin{array}{c}0,049 \pm 0,002 \\
\quad(11)\end{array}$ & $\begin{array}{l}0,044 \pm 0,001 * \\
\quad(20)\end{array}$ & $\begin{array}{c}0,042 \pm 0,002 * * \\
(15)\end{array}$ & $\begin{array}{c}0,044 \pm 0,001 * \\
\quad(16)\end{array}$ \\
\hline Food intake (g\%) & $\begin{array}{c}9,33 \pm 0,44 \\
(12)\end{array}$ & $\begin{array}{c}7,32 \pm 0,33 * \\
(18)\end{array}$ & $\begin{array}{c}8,37 \pm 0,27 \\
(8)\end{array}$ & $\begin{array}{c}6,39 \pm 0,48^{* *} \\
(8)\end{array}$ \\
\hline
\end{tabular}


$* \mathrm{p}<0.05 ; * * \mathrm{p}<0.01$ and $* * * \mathrm{p}<0.001$ vs healthy (One-Way ANOVA followed by Tukey). The values in parentheses indicate the number of animals. 


\section{FIGURE CAPTIONS}

Figure 1. $\mathrm{p}-\mathrm{Akt}^{\mathrm{Ser} 473}$ :total $\mathrm{Akt}$ in retroperitoneal fat (A), mesenteric fat (B) and gastrocnemius muscle $(\mathrm{C})$ in healthy rats and Walker-256 tumor-bearing rats treated with metformin (Tumor + MET), metformin plus insulin (Tumor + MET + INS) or with vehicles for 12 days. The proteins were normalized by $\gamma$-tubulin. Data are mean \pm SEM of $8-12$ fed rats. ${ }^{*} \mathrm{p}<0.05 ;{ }^{*} \mathrm{p}<0.01$ and $* * * \mathrm{p}<0.001 v s$ healthy (One-Way ANOVA followed by Tukey).

Figure 2. Glycemia (A) and constant of serum glucose disappearance (KITT) (B) of healthy rats and Walker-256 tumor-bearing rats treated with metformin (Tumor + MET), metformin plus insulin (Tumor + MET + INS) or with vehicles for 12 days. Glycemia was evaluated at 0 (basal), 5,10 and 15 minutes after the injection of regular insulin $\left(0.25 \mathrm{UI} \cdot \mathrm{kg}^{-1}\right)$. Data are mean $\pm \mathrm{SEM}$ of 5-15 fed rats. The glycemia values within the same group were compared to basal ( 0 min) by repeated measures ANOVA followed by Tukey; ***p $<0.01$. Differences between kITTs: $* \mathrm{p}<0.05$ and $* * \mathrm{p}<0.01$ versus healthy (One-way ANOVA followed by Tukey).

Figure 3. Plasma insulin (A), insulin secretion-stimulated by 5.6, 11.1 and $16.7 \mathrm{mM}$ glucose (B) and the respective intracellular insulin content (C), after $1 \mathrm{~h}$ of incubation of the islets, of healthy and Walker-256 tumor-bearing rats treated with metformin (Tumor + MET) or with metformin plus insulin (Tumor + MET + INS) or with vehicles for 12 days. Data are mean \pm SEM of 4-8 fed rats. ${ }^{*} \mathrm{p}<0.05, * * \mathrm{p}<0.01$ and $* * * \mathrm{p}<0.001 v s$ healthy (One-Way ANOVA followed by Tukey).

Figure 4. Production of lactate (A), production pyruvate (B) and glycolysis (C) from exogenous glucose, and areas under curves (AUCs) (D), in livers of healthy rats and Walker-256 tumorbearing rats treated with metformin (Tumor + MET), metformin plus insulin (Tumor + MET + INS) or with vehicles for 12 days. Livers were perfused as described in Material and Methods. Glucose $(20 \mathrm{mM})$ was infused between 10 and $40 \mathrm{~min}$. Data are mean \pm SEM of 5-6 rats fasted 
24 hours. ${ }^{*} \mathrm{p}<0.05 ; * * \mathrm{p}<0.01$ and $* * * \mathrm{p}<0.001$ vs healthy (One-Way ANOVA followed by Tukey).

Figure 5. Production of glucose (A), glycogenolysis (B) and the means of glucose production (C) and glycogenolysis (D) in livers of healthy rats and Walker-256 tumor-bearing rats treated with metformin (Tumor + MET), metformin plus insulin (Tumor + MET + INS) or with vehicles for 12 days. Livers were perfused as described in Materials and Methods. Data are mean \pm SEM of 3-7 fed rats. ${ }^{*} \mathrm{p}<0.05 ;{ }^{* *} \mathrm{p}<0.01$ and ${ }^{* * *} \mathrm{p}<0.001$ vs healthy; ${ }^{\# \#} \mathrm{p}<0.001$ vs tumor (One-Way ANOVA followed by Tukey).

Figure 6. Production of glucose (A), lactate (B) and pyruvate (C) from alanine, and areas under curves (D), in livers of healthy rats and Walker-256 tumor-bearing rats treated with metformin $($ Tumor + MET), metformin plus insulin (Tumor + MET + INS) or with vehicles for 12 days. Livers were perfused as described in Material and Methods. Alanine $(2.5 \mathrm{mM})$ was infused between 10 and $40 \mathrm{~min}$. Data are mean \pm SEM of $5-6$ rats fasted 24 hours. ${ }^{*} p<0.05 ; * *^{*}<0.01 v s$ healthy; ${ }^{\#}<0.05$ and ${ }^{\# \# \#} \mathrm{p}<0,001$ vs tumor (One-Way ANOVA followed by Tukey). 


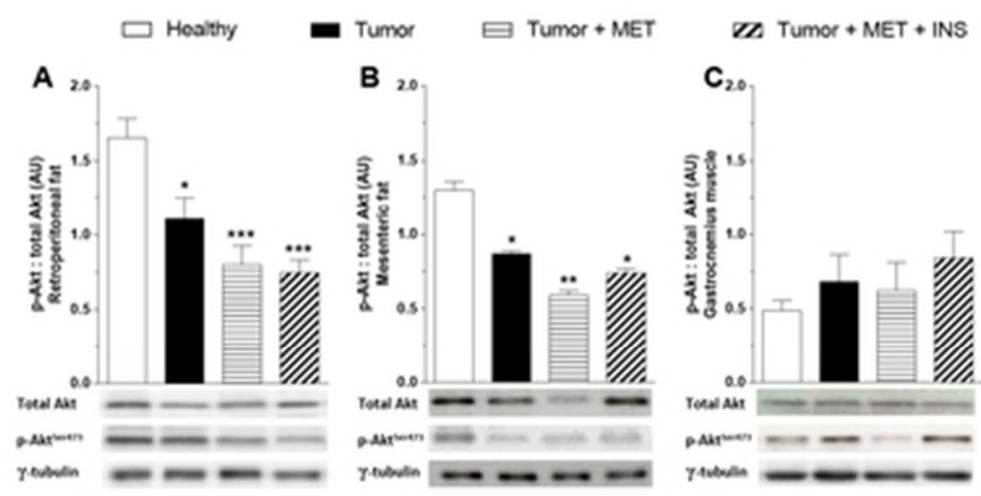

Figure 1

$32 \times 17 \mathrm{~mm}(300 \times 300 \mathrm{DPI})$ 


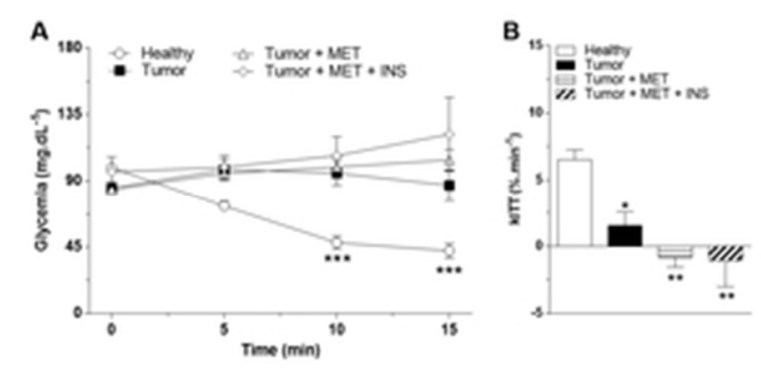

Figure 2

$25 \times 12 \mathrm{~mm}(300 \times 300 \mathrm{DPI})$ 

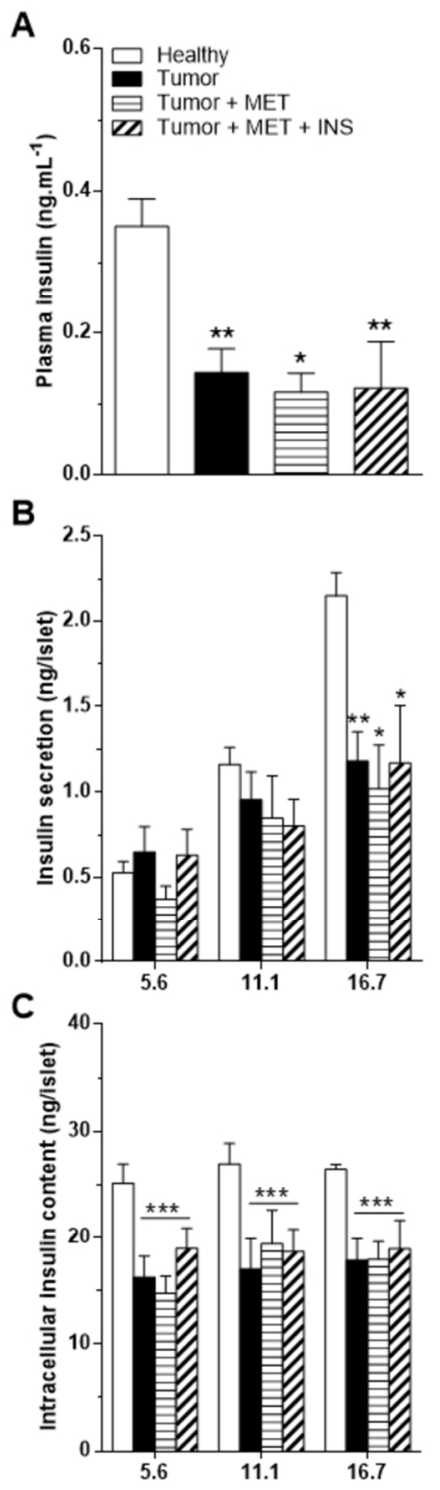

Figure 3

$42 \times 124 \mathrm{~mm}(300 \times 300 \mathrm{DPI})$ 


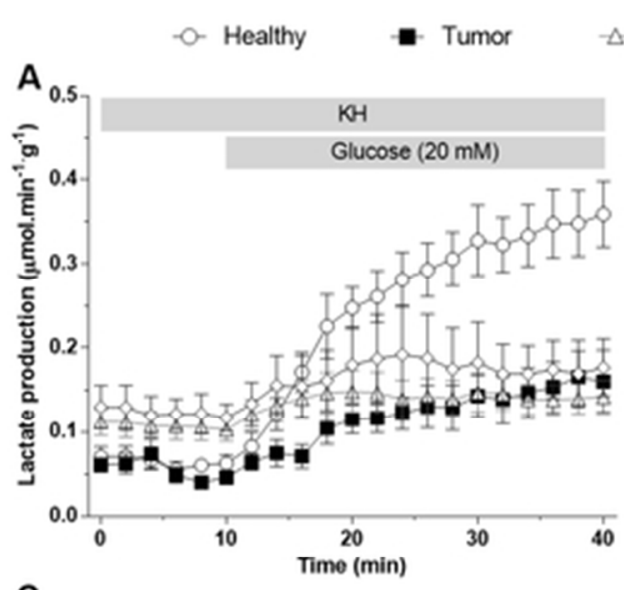

$\triangle$ Tumor + MET $\quad \diamond$ Tumor + MET + INS
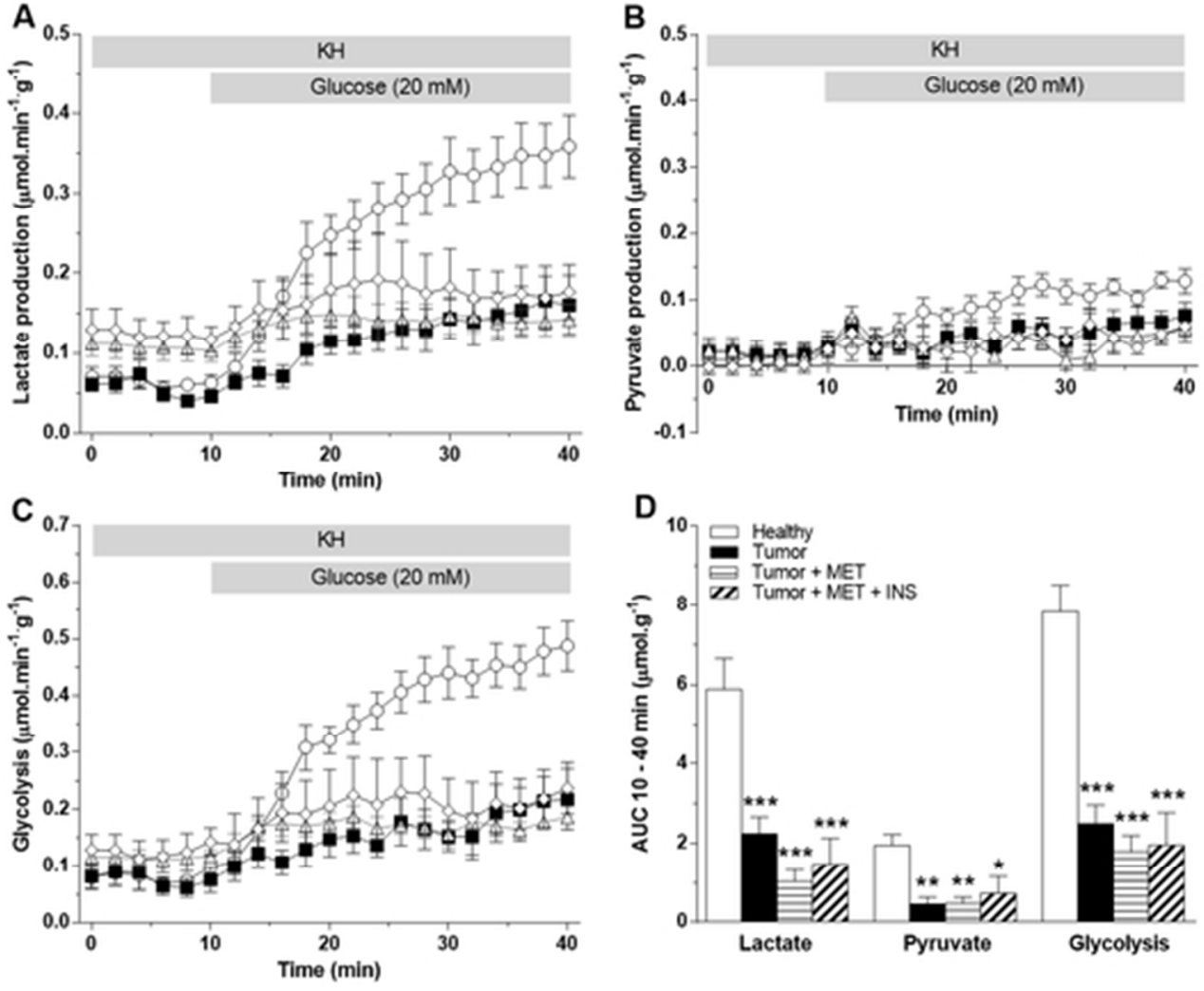

Figure 4

$45 \times 38 \mathrm{~mm}(300 \times 300 \mathrm{DPI})$ 

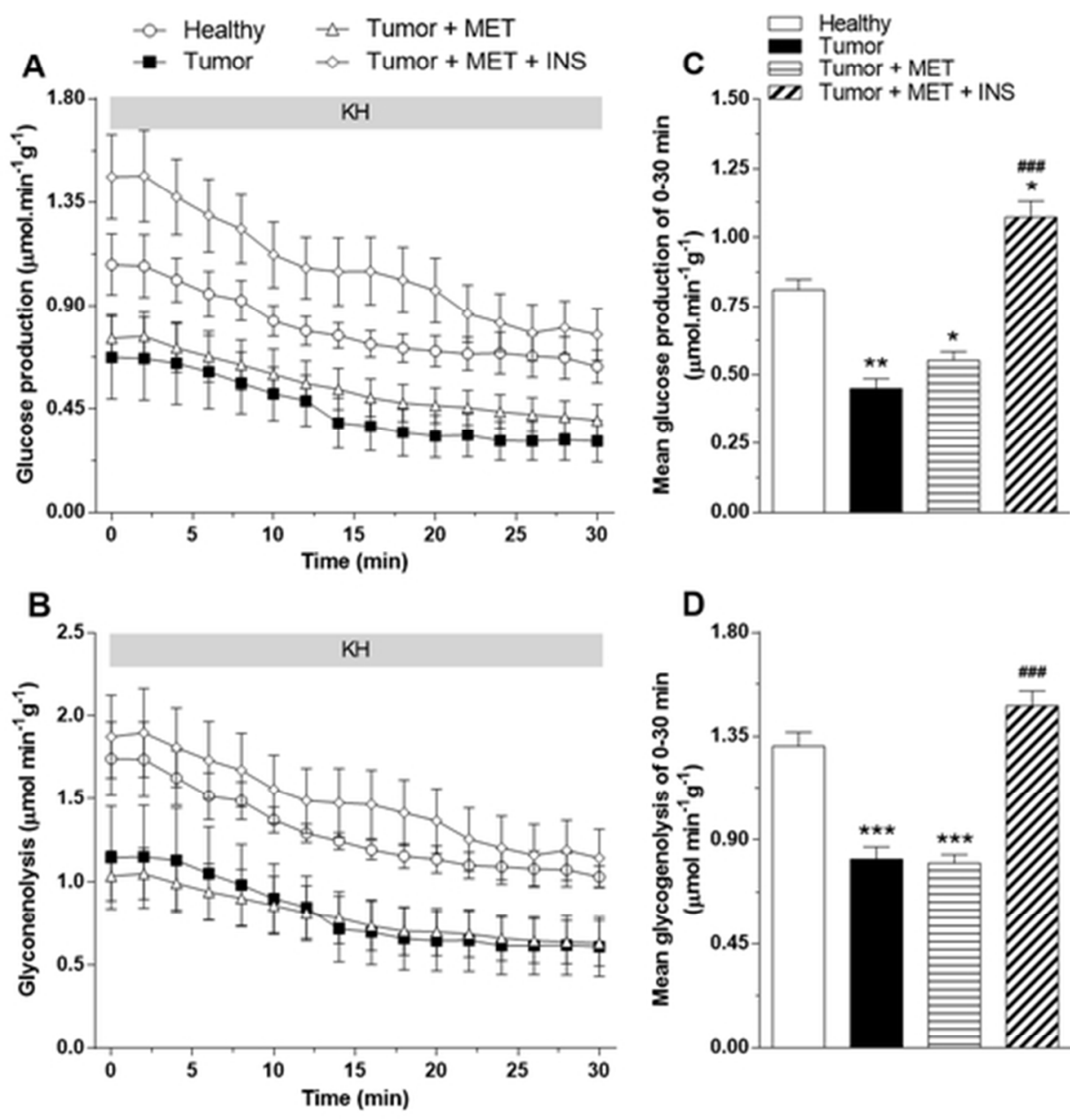

Figure 5

$48 \times 50 \mathrm{~mm}(300 \times 300$ DPI $)$ 


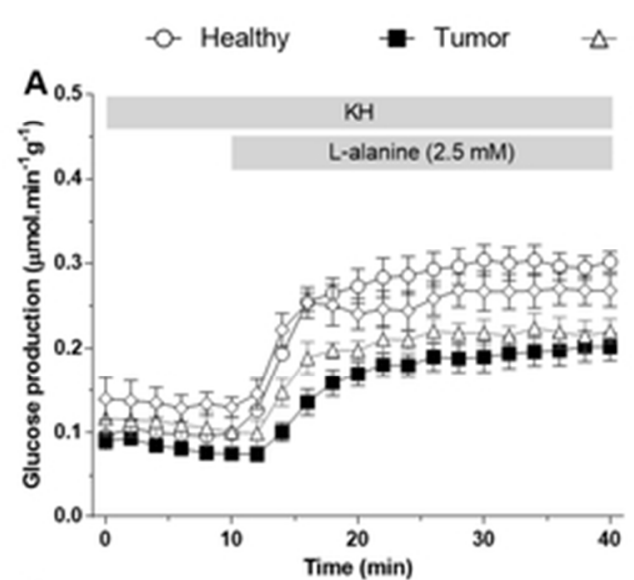

$\checkmark$ Tumor + MET $\prec$ Tumor + MET + INS
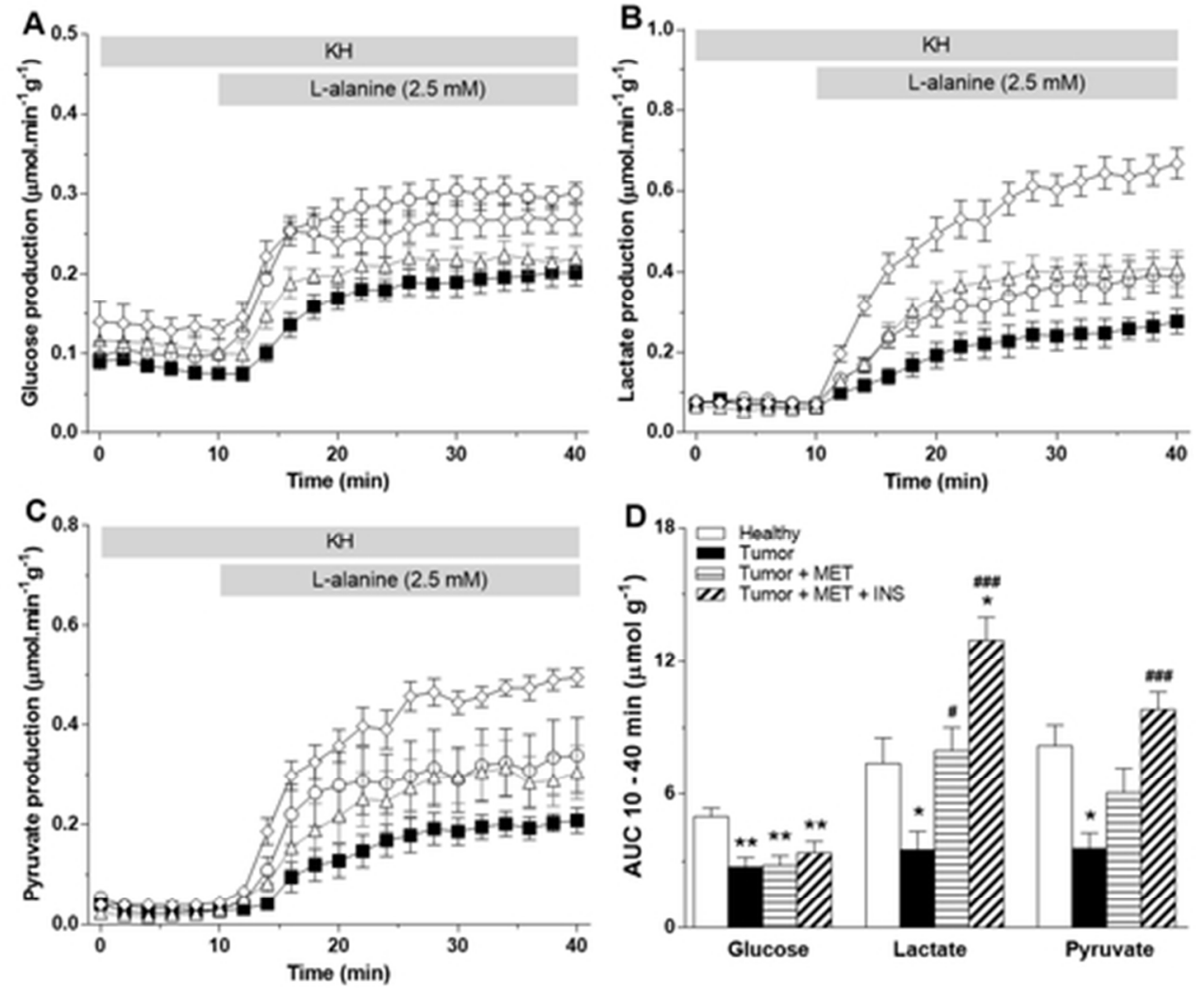

Figure 6

$44 \times 38 \mathrm{~mm}(300 \times 300 \mathrm{DPI})$ 